Wright State University

CORE Scholar

Physics Faculty Publications

Physics

8-1-1999

\title{
Production and Annealing of Electron Irradiation Damage in $\mathrm{ZnO}$
}

David C. Look

Wright State University - Main Campus, david.look@wright.edu

D. C. Reynolds

Joseph W. Hemsky

Wright State University - Main Campus, joseph.hemsky@wright.edu

R. L. Jones

J. R. Sizelove

Follow this and additional works at: https://corescholar.libraries.wright.edu/physics

Part of the Physics Commons

\section{Repository Citation}

Look, D. C., Reynolds, D. C., Hemsky, J. W., Jones, R. L., \& Sizelove, J. R. (1999). Production and Annealing of Electron Irradiation Damage in ZnO. Applied Physics Letters, 75 (6), 811-813.

https://corescholar.libraries.wright.edu/physics/60

This Article is brought to you for free and open access by the Physics at CORE Scholar. It has been accepted for inclusion in Physics Faculty Publications by an authorized administrator of CORE Scholar. For more information, please contact library-corescholar@wright.edu. 


\title{
Production and annealing of electron irradiation damage in $\mathrm{ZnO}$
}

\author{
D. C. Look, a) D. C. Reynolds, and J. W. Hemsky \\ Semiconductor Research Center, Wright State University, Dayton, Ohio 45435 \\ R. L. Jones and J. R. Sizelove \\ Materials and Manufacturing Directorate, Air Force Research Laboratory, \\ Wright-Patterson Air Force Base, Ohio 45433
}

(Received 6 May 1999; accepted for publication 14 June 1999)

\begin{abstract}
High-energy $(>1.6 \mathrm{MeV})$ electrons create acceptors and donors in single-crystal $\mathrm{ZnO}$. Greater damage is observed for irradiation in the [0001] direction ( $\mathrm{Zn}$ face) than in the [0001] direction $(\mathrm{O}$ face). The major annealing stage occurs at about $300-325^{\circ} \mathrm{C}$, and is much sharper for defects produced by Zn-face irradiation, than for those resulting from O-face irradiation. The defects appear to have a chain character, rather than being simple, near-neighbor vacancy/interstitial Frenkel pairs. These experiments suggest that $\mathrm{ZnO}$ is significantly more "radiation hard" than $\mathrm{Si}, \mathrm{GaAs}$, or $\mathrm{GaN}$, and should be useful for applications in high-irradiation environments, such as electronics in space satellites. () 1999 American Institute of Physics. [S0003-6951(99)04232-1]
\end{abstract}

Wurtzitic $\mathrm{ZnO}$ is a high-band gap $(3.437 \mathrm{eV}$ at $2 \mathrm{~K})$ semiconductor which has many applications, such as piezoelectric transducers, varistors, ${ }^{1}$ phosphors, and transparent conducting films. Most of these applications require only polycrystalline material; however, recent successes in producing large-area single crystals ${ }^{2}$ have opened up the possibility of producing blue and UV light emitters, ${ }^{3}$ and hightemperature, high-power transistors. The main advantages of $\mathrm{ZnO}$ as a light emitter are its large exciton binding energy $(60 \mathrm{meV})$, and the existence of well-developed bulk and epitaxial growth processes; for electronic applications, its attractiveness lies in having high breakdown strength and high saturation velocity. Optical UV lasing, at both low and high temperatures, has already been demonstrated, ${ }^{3,4}$ although efficient electrical lasing must await the further development of good, $p$-type material. ${ }^{5}$

For space-based applications, especially those in nearearth orbit, it is important to have radiation-resistant materials. In particular, the Van Allen belt contains high fluxes of electrons $(0-10 \mathrm{MeV})$, and protons $(>10 \mathrm{MeV})$. In the present study, we have used a Van de Graaff accelerator to obtain high-energy electrons, and have measured the changes in the electrical and optical properties as a function of bombardment energy (1-2 MeV) and annealing temperature $\left(250-800^{\circ} \mathrm{C}\right)$. The conclusion is that $\mathrm{ZnO}$ may be much more resistant to radiation damage than are other common semiconductor materials, such as $\mathrm{Si}, \mathrm{GaAs}, \mathrm{CdS}$, and $\mathrm{GaN}$. This fact, coupled with the excellent optical and electrical properties mentioned earlier, would seem to suggest that $\mathrm{ZnO}$ devices should be pursued for space applications.

The $\mathrm{ZnO}$ samples used here were $6 \mathrm{~mm} \times 6 \mathrm{~mm} \times 0.5 \mathrm{~mm}$ pieces cut from 2 in. wafers, which themselves were sliced from boules grown by a seeded vapor transport technique. The wafer surfaces were oriented perpendicular to the crystalline $c$ axis; thus, the bombarding electrons could be directed onto the (0001) $\mathrm{Zn}$ face, or the (0001) O face. Con-

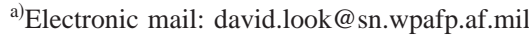

sider the (0001) plane, in which a layer of $\mathrm{Zn}$ atoms is on top. An electron impinging on this face, and displacing a $\mathrm{Zn}$ atom, knocks it into an interstitial region, forming a simple Frenkel pair; however, an electron hitting the opposite face has a more difficult time displacing the $\mathrm{Zn}$ atom, because, in this direction, each $\mathrm{Zn}$ atom has a short-bonded $\mathrm{O}$ atom immediately beneath it. ${ }^{6}$ The reverse conclusions hold for O-atom displacement; thus, the "easy" direction for $\mathrm{Zn}$ atom displacement is [0001] and the easy direction for $\mathrm{O}$-atom displacement is $[000 \overline{1}]$. From these considerations, we might expect different defects to be created for different irradiation directions, and that indeed is the case. However, defect annihilations, primarily due to Coulombic attractions, must also be taken into account.

The $\mathrm{ZnO}$ crystals, grown by Eagle-Picher, Inc., were of very high quality, with $300 \mathrm{~K}$ and peak Hall mobilities of about 225 and $2000 \mathrm{~cm}^{2} / \mathrm{V} \mathrm{s}$, respectively, and photoluminescence (PL) donor-bound-exciton linewidths of $<0.3$ $\mathrm{meV}{ }^{7}$ Electrical properties, determined from temperaturedependent Hall effect (TDH) analysis, were similar to those reported previously: ${ }^{2}$ two donors, with approximate energies 30 and $60 \mathrm{meV}$, respectively, and concentrations of $1 \times 10^{16}$ and $1 \times 10^{17} \mathrm{~cm}^{-3}$, respectively, and an acceptor of concentration $2 \times 10^{15} \mathrm{~cm}^{-3}$. The irradiations were performed under vacuum, with the sample mounted on a watercooled stage; the energies were $1.0-2.0 \mathrm{MeV}$ and the current densities were typically $2-6 \mu \mathrm{A} / \mathrm{cm}^{2}$. The fluence at each energy was kept constant at $4 \times 10^{16} \mathrm{~cm}^{-2}$. After the sequence of irradiations was complete, the samples were subjected to annealing steps at temperatures of $250-800{ }^{\circ} \mathrm{C}$. Each anneal was carried out for $10 \mathrm{~min}$., in flowing $\mathrm{N}_{2}$. Sample EP97027 was irradiated on the $\mathrm{Zn}$ face, and sample EP97036, on the O face. Although the two samples came from different boules, their initial electrical and optical properties were nearly identical.

The total sequence of irradiations and anneals, for each sample, is designated as follows: (1) as-grown; (2) $1.0 \mathrm{MeV}$; (3) $1.3 \mathrm{MeV}$; (4) $1.6 \mathrm{MeV}$; (5) $2.0 \mathrm{MeV}$; (6) $2.0 \mathrm{MeV}$; (7) $2.0 \mathrm{MeV}$; (8) $2.0 \mathrm{MeV}$; (9) $250{ }^{\circ} \mathrm{C}$; (10) $300{ }^{\circ} \mathrm{C}$; (11) $350{ }^{\circ} \mathrm{C}$; 


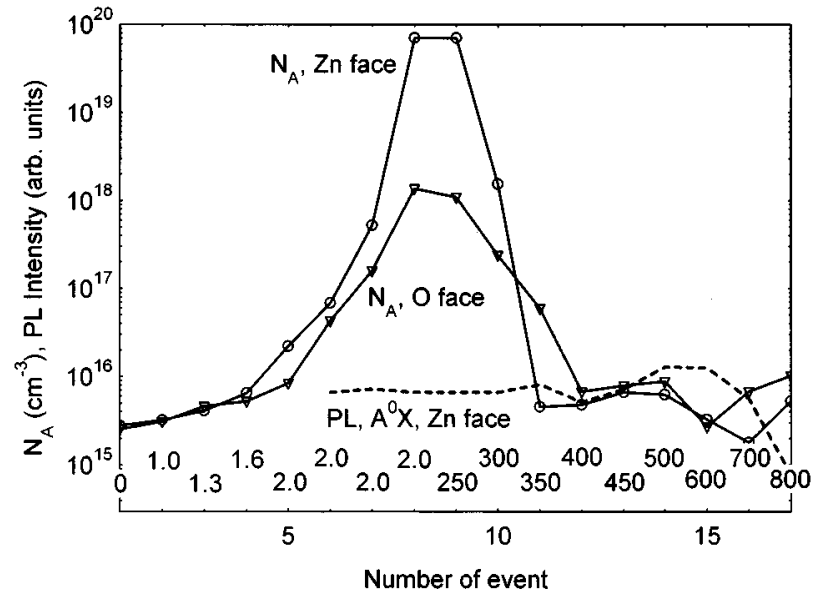

FIG. 1. Acceptor concentration measured after electron irradiation events (Nos. 1-8; energies in eV), and annealing events (Nos. 9-17; temperatures in ${ }^{\circ} \mathrm{C}$ ). Also shown is the intensity of the $A^{0} X$ photoluminescence spectrum, normalized by the $D^{0} X$ spectrum in order to eliminate nonradiative effects. The solid and dashed lines are simply meant to guide the eye.

(12) $400{ }^{\circ} \mathrm{C}$; (13) $450{ }^{\circ} \mathrm{C}$; (14) $500{ }^{\circ} \mathrm{C}$; (15) $600{ }^{\circ} \mathrm{C}$; (16) $700{ }^{\circ} \mathrm{C}$; (17) $800^{\circ} \mathrm{C}$. In Fig. 1, we present Hall effect and PL data as a function of event number. The acceptor concentration $N_{A}$ is chosen as the Hall effect parameter of interest, because $N_{A}$ is well fitted from temperature-dependent mobility data, whereas the fits of $N_{D}$ depend, of course, on how many donors are assumed to be present. (See Refs. 2 and 8 for a description of the methodology used to fit the TDH data.) For a comparison of $N_{A}$ with PL data, the integrated acceptor-bound-exciton $\left(A^{0} X\right)$ spectrum was chosen, since acceptors are involved in each case. Actually, the $A^{0} X$ data are normalized by using the $D^{0} X$ data as a divisor, since then the effects of nonradiative centers are largely removed.

We first note, from Fig. 1, that very little increase in $N_{A}$ takes place for electron-bombardment energies up to 1.6 $\mathrm{MeV}$. The same holds true for the PL intensities (not shown), which have decreased less than a factor-two after the 1.6 $\mathrm{MeV}$ irradiation. (It is also important to note that each irradiation in the sequence involves a rather large dose, $4 \times 10^{16} \mathrm{~cm}^{-2}$.) This fact shows that $c$-axis-irradiated $\mathrm{ZnO}$ experiences much less damage from high-energy electrons than does its counterparts, Si, GaAs, CdS, or even GaN. As argued in a previous paper, ${ }^{8}$ such a high $(>1.6 \mathrm{MeV})$ damage threshold cannot be explained by simple, nearestneighbor Frenkel-pair production, because such a process would require unrealistically high atomic displacement energies (133 eV for $\mathrm{Zn}, 484 \mathrm{eV}$ for O). Instead, multiple displacements must be required to produce stable defects. In fact, by using Van Vechten's theoretical displacement energies (18.5 eV for $\mathrm{Zn}, 41.4 \mathrm{eV}$ for O) ${ }^{9}$ along with a formula derived in Ref. 8, a three-displacement chain ( $\mathrm{Zn}-\mathrm{O}-\mathrm{Zn}$ ) would require $1.55 \mathrm{MeV}$, in good agreement with experiment. The final defect in this case might be a $V_{\mathrm{Zn}}-\mathrm{Zn}_{\mathrm{O}}-\mathrm{O}_{\mathrm{Zn}}-\mathrm{Zn}_{I}$ complex, with the $\mathrm{Zn}_{I}$ perhaps being knocked away from the rest of the complex. The idea here is that the positively charged $\mathrm{Zn}_{I}$ must be more than a nearestneighbor distance away from the negatively charged $V_{\mathrm{Zn}}$ to avoid immediate recombination, so that the simple $V_{\mathrm{Zn}}-\mathrm{Zn}_{I}$ Frenkel pair would be unstable. If the chain defect suggested above is accurate, then the acceptor might be $V_{\mathrm{Zn}}-\mathrm{Zn}_{\mathrm{O}}-\mathrm{O}_{\mathrm{Zn}}$ and the donor, $\mathrm{Zn}_{I}$. To be more complete in these arguments, we must consider other possible chain defects. For $\mathrm{Zn}$-face irradiation, we can calculate the following threshold energies: $0.38 \mathrm{MeV}$ for $\mathrm{O}-\mathrm{Zn}$; $0.40 \mathrm{MeV}$ for $\mathrm{Zn}$ alone; 0.94 $\mathrm{MeV}$ for $\mathrm{O}-\mathrm{Zn}-\mathrm{O}-\mathrm{Zn}$; $1.55 \mathrm{MeV}$ for $\mathrm{Zn}-\mathrm{O}-\mathrm{Zn}$; and 1.81 $\mathrm{MeV}$ for $\mathrm{O}-\mathrm{Zn}-\mathrm{O}-\mathrm{Zn}-\mathrm{O}-\mathrm{Zn}$. For $\mathrm{O}$ face irradiation, we get: $0.24 \mathrm{MeV}$ for $\mathrm{O}$ alone; $0.74 \mathrm{MeV}$ for $\mathrm{O}-\mathrm{Zn}-\mathrm{O} ; 1.17$ $\mathrm{MeV}$ for $\mathrm{Zn}-\mathrm{O} ; 1.50 \mathrm{MeV}$ for $\mathrm{O}-\mathrm{Zn}-\mathrm{O}-\mathrm{Zn}-\mathrm{O}$; and 2.53 $\mathrm{MeV}$ for $\mathrm{Zn}-\mathrm{O}-\mathrm{Zn}-\mathrm{O}$. Other, longer chains could be formed for energies above $3 \mathrm{MeV}$. Suppose we postulate that each atom displaced simply replaces the atom below it, if it has enough kinetic energy to knock out that particular atom; then, as discussed above, the $\mathrm{Zn}-\mathrm{O}-\mathrm{Zn}$ sequence would produce the defect $V_{\mathrm{Zn}}-\mathrm{Zn}_{\mathrm{O}}-\mathrm{O}_{\mathrm{Zn}}-\mathrm{Zn}_{I}$. Now it is likely that $V_{\mathrm{Zn}}$ has acceptor states close to the valence band, as is true for most of the cation vacancies in the II-VI and III-V compounds; thus, although we do not know the donor/ acceptor nature of some of the other possible defects, it is quite reasonable to assume that the acceptor defect observed in Fig. 1 is related to $V_{\mathrm{Zn}}$. If we also postulate that a chain of at least three displacements is necessary to avoid Coulombic annihilation, then the lowest-threshold surviving defects should be $\mathrm{Zn}-\mathrm{O}-\mathrm{Zn}$, for $\mathrm{Zn}$-face irradiation, and $\mathrm{Zn}-\mathrm{O}-$ $\mathrm{Zn}-\mathrm{O}$, for O-face irradiation. This model would predict a threshold energy of $1.55 \mathrm{MeV}$ in the former case, and 2.53 $\mathrm{MeV}$, in the latter. Indeed, the $1.55-\mathrm{MeV}$ threshold is observed in Fig. 1 for Zn-face irradiation, and a higher threshold, about $2 \mathrm{MeV}$, is found for O-face irradiation. From standard theory, ${ }^{10}$ we can calculate $\mathrm{Zn}$ displacement rates of 1.7 and $1.9 \mathrm{~cm}^{-1}$ at these energies; however, the $\mathrm{O}$ displacement rate, at say $1.6 \mathrm{MeV}$, is only about $0.23 \mathrm{~cm}^{-1}$, nearly an order-of-magnitude lower. This is another reason to believe that the acceptor-defect production begins with a $\mathrm{Zn}$, rather than an $\mathrm{O}$, displacement.

Another observation is that the $N_{A}$ determined from the Hall-effect measurements does not correlate well with the $A^{0} X$ PL spectrum over the region of high $N_{A}$ production (i.e., for electron energies $>1.6 \mathrm{MeV}$ ). This fact suggests that the excitons are still binding to preexisting "shallow" ( $\sim 200 \mathrm{meV}$ ) acceptors, rather than to the irradiation-induced acceptors, which are probably much deeper. There appears to be some correlation between PL and Hall data in the 400$600{ }^{\circ} \mathrm{C}$ anneal region, but, by then, most of the irradiationinduced acceptors have annealed out.

Finally, we consider the dominant $N_{A}$ annealing stage at about $325^{\circ} \mathrm{C}$. Clearly, the annealing after Zn-face irradiation is much sharper than that after $\mathrm{O}$-face irradiation. If each defect anneals (annihilates) independently, then the isochronal annealing process for a defect of concentration $N$ can be described as follows: ${ }^{11}$

$$
N_{i+1}=N_{\infty}+\left(N_{i}-N_{\infty}\right) \exp \left[-\nu \tau \exp \left(-E_{A} / k T_{i}\right)\right]
$$

where the subscript $i=0,1,2 \ldots$. denotes the annealing step $\left[T_{0}=298.2 \mathrm{~K}\left(25^{\circ} \mathrm{C}\right), T_{1}=523.2 \mathrm{~K}\left(250^{\circ} \mathrm{C}\right)\right.$, etc. $], \tau=600 \mathrm{~s}$ is the annealing time, $\nu$ is a frequency factor $\left(\nu=10^{13} \mathrm{~s}^{-1}\right.$, as commonly assumed), and $E_{A}=E_{A_{0}}+\alpha\left(T_{i}-T_{1}\right)$ is the activation energy. The parameter $\alpha$ allows for a change in $E_{A}$ as 


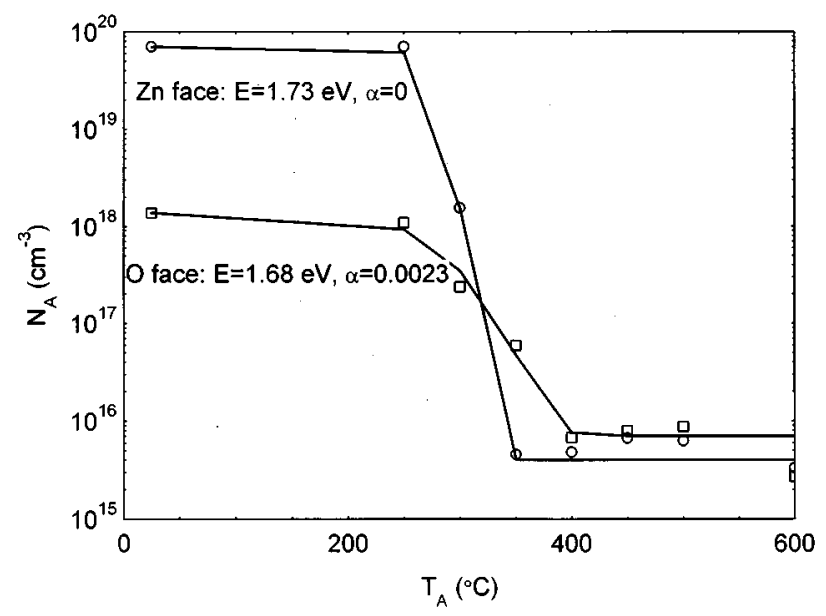

FIG. 2. Acceptor concentration, as a function of annealing temperature, for samples irradiated on the $\mathrm{Zn}$ face, and the $\mathrm{O}$ face, respectively. The solid lines are theoretical fits, using first-order kinetics, with activation energy parameterized by $E_{A}=E+\alpha T$.

a function of annealing temperature $T_{i}$; such a change might be expected if more than one type of defect is present.

The annealing data and theoretical fits are shown in Fig. 2. The fit to the $\mathrm{Zn}$-face-irradiated sample is remarkable, because it is accomplished with $\alpha=0$, strongly suggesting that only one type of defect is created by $2-\mathrm{MeV}$-electron irradiation on this face, and that the annealing process is simply a collapse of this defect. For the particular defect proposed earlier, the annealing process would be: $V_{\mathrm{Zn}}-\mathrm{Zn}_{\mathrm{O}}-\mathrm{O}_{\mathrm{Zn}}-\mathrm{Zn}_{I} \rightarrow \mathrm{Zn}_{\mathrm{Zn}}-\mathrm{O}_{\mathrm{O}}-\mathrm{Zn}_{\mathrm{Zn}}$, with a fitted activation energy of $1.73 \mathrm{eV}$. For the $\mathrm{O}$-face irradiation, on the other hand, the best fit gives $\alpha=0.0023$, which implies the existence of more than one type of defect, with activation energies ranging from $1.68 \mathrm{eV}$, at the beginning of the anneal, to about $2.03 \mathrm{eV}$ at the end (at about $400{ }^{\circ} \mathrm{C}$ ). Even if a second-order (uncorrelated) annealing process is assumed for the O-face case, a good fit cannot be obtained for $\alpha=0$. Thus, we believe that a single type of defect dominates for 2-MeV Zn-face irradiation, and more than one type of defect for O-face irradiation.

As discussed in a previous report, ${ }^{8}$ an interesting aspect of the present experiments is that the electronic activation energy of the dominant donor produced by the irradiation, about $30 \mathrm{meV}$, is close to that found in most high-quality $\mathrm{ZnO}$ crystals produced in recent times, and also in the past. $^{2,12}$ Thus, we believe that the native shallow donor is a $\mathrm{Zn}$-sublattice defect, probably involving $\mathrm{Zn}_{I}$, and is not the
O vacancy, as has been commonly assumed by many in the past. ${ }^{13}$ Another important aspect, of practical importance, is that electrical and optical damage is minimal even at rather high electron energies $(\geqslant 1.6 \mathrm{MeV})$, and fluences $(\geqslant 1$ $\times 10^{17} \mathrm{~cm}^{-2}$ ). Thus, these preliminary experiments indicate that $\mathrm{ZnO}$ devices should be useful in high-irradiation environments, such as those found in space applications.

In summary, we have presented electrical and optical data on $\mathrm{ZnO}$ crystals irradiated with high-energy electrons. Electrical damage is minimal up to energies of $1.6 \mathrm{MeV}$, and optical damage, to even higher energies. For 2-MeV Zn-face irradiation, a single type of defect is produced, and this defect anneals out at about $300-325^{\circ} \mathrm{C}$, with an activation energy of $1.73 \mathrm{eV}$. The total defect concentration is lower for O-face irradiation, although more than one type of defect is produced. The high damage-threshold energy (1.6 MeV) suggests that $\mathrm{ZnO}$ devices should be useful for radiation environments.

The authors wish to thank T. A. Cooper, D. Beasley, and L. Callahan for technical assistance, C. W. Litton for helpful discussions, and C. Huang for support and encouragement. D.C.L., D.C.R., and J.W.H. were supported under U.S. Air Force Contract No. F33615-95-C-1619, and some of their work was performed at the Air Force Research Laboratory, Wright-Patterson Air Force Base, OH. Also, partial support was received from the Air Force Office of Scientific Research.

${ }^{1}$ Y. P. Wang, W. I. Lee, and T.-Y. Tseng, Appl. Phys. Lett. 69, 1807 (1996).

${ }^{2}$ D. C. Look, D. C. Reynolds, J. R. Sizelove, R. L. Jones, C. W. Litton, G. Cantwell, and W. C. Harsch, Solid State Commun. 105, 399 (1998).

${ }^{3}$ D. C. Reynolds, D. C. Look, and B. Jogai, Solid State Commun. 99, 873 (1996).

${ }^{4}$ D. M. Bagnall, Y. F. Chen, Z. Zhu, T. Yao, S. Koyama, M. Y. Shen, and T. Goto, Appl. Phys. Lett. 70, 2230 (1997).

${ }^{5}$ K. Minegishi, Y. Koiwai, and Y. Kikuchi, Jpn. J. Appl. Phys., Part 2 36, L1453 (1997).

${ }^{6}$ D. Pons and J. C. Bourgoin, J. Phys. C 18, 3839 (1985).

${ }^{7}$ D. C. Reynolds, D. C. Look, B. Jogai, C. W. Litton, T. C. Collins, W. C. Harsch, and G. Cantwell, Phys. Rev. B 57, 12151 (1998).

${ }^{8}$ D. C. Look, J. W. Hemsky, and J. R. Sizelove, Phys. Rev. Lett. 82, 2552 (1999).

${ }^{9}$ J. A. Van Vechten, in Handbook on Semiconductors, edited by T. S. Moss and S. P. Keller (North-Holland, Amsterdam, 1980), Chap. 1.

${ }^{10}$ F. Agullo-Lopez, C. R. A. Catlow, and P. D. Townsend, Point Defects in Materials (Academic, New York, 1988).

${ }^{11}$ B. T. Kelly, Irradiation Damage to Solids (Pergamon, Oxford, 1966), p. 181.

${ }^{12}$ P. Wagner and R. Helbig, J. Phys. Chem. Solids 35, 327 (1974).

${ }^{13}$ F. A. Kröger, The Chemistry of Imperfect Crystals (North-Holland, Amsterdam, 1974). 